\title{
Deciphering the Enigmatic Function of Pseudomonas Metallothioneins
}

\author{
Jelena Habjanič ${ }^{1}$, Anugraha Mathew ${ }^{2}$, Leo Eberl ${ }^{2 *}$ and Eva Freisinger ${ }^{1 *}$ \\ ${ }^{1}$ Department of Chemistry, University of Zurich, Zurich, Switzerland, ${ }^{2}$ Department of Plant and Microbial Biology, University \\ of Zurich, Zurich, Switzerland
}

Metallothioneins (MTs) are low molecular weight, Cys-rich proteins that sequester both essential and non-essential metal ions. Despite being highly conserved in the Pseudomonas genus of Gram-negative bacteria, knowledge of their physiological function in this species is scarce. Using the strain P. fluorescens Q2-87 as a model organism, we investigated the role of a conserved MT in zinc homeostasis, cadmium detoxification as well as its implications in stress response. We show that MT expression is only induced in the stationary phase and provides a fitness benefit for long-term starvation survival, while it is not required for metal resistance and acquisition, oxidative or nitrosative stress response, biofilm formation or motility.

\section{OPEN ACCESS}

Edited by:

Hari S. Misra,

Bhabha Atomic Research Centre (BARC), India

Reviewed by:

Reinhard Dallinger,

University of Innsbruck, Austria Claudia Andrea Blindauer

University of Warwick, United Kingdom

*Correspondence: Leo Eberl leberl@botinst.uzh.ch Eva Freisinger

freisinger@chem.uzh.ch

Specialty section:

This article was submitted to Microbial Physiology and Metabolism,

a section of the journal Frontiers in Microbiology

Received: 11 May 2020 Accepted: 29 June 2020

Published: 22 July 2020

Citation:

Habjanič J, Mathew A, Eberl L and Freisinger $E$ (2020) Deciphering the Enigmatic Function

of Pseudomonas Metallothioneins.

Front. Microbiol. 11:1709.

doi: 10.3389/fmicb.2020.01709
Keywords: metallothionein, Pseudomonas fluorescens, stationary phase, long-term viability, zinc, cadmium

\section{INTRODUCTION}

$\mathrm{Zn}^{\mathrm{II}}$ is considered to be an essential metal ion playing a role as a catalytic or structural cofactor of many key enzymes involved in DNA replication, protein synthesis, and other crucial enzymatic reactions in all organisms. However, zinc is toxic in excess and bacteria have evolved various mechanisms to tightly regulate the intracellular concentration of this metal, keeping the free zinc concentration extremely low (femto- to picomolar range) (Blindauer, 2015; Watly et al., 2016; Mikhaylina et al., 2018). $\mathrm{Cd}^{\mathrm{II}}$ is highly toxic for most organisms and its acute toxicity is closely associated with oxidative stress (Maret and Moulis, 2013). In addition, while $\mathrm{Cd}^{\mathrm{II}}$ is highly similar to $\mathrm{Zn}^{\mathrm{II}}$ with respect to coordination preferences and redox inactivity, it is also more thiophilic and hence displaces $\mathrm{Zn}^{\mathrm{II}}$ efficiently in the corresponding biologically relevant binding sites. Therefore, bacteria have developed various metal uptake and efflux systems to finely regulate metal ion homeostasis.

Metallothioneins (MTs), low molecular weight Cys-rich proteins, are one of the important partakers in maintaining zinc or copper homeostasis as well as cadmium detoxification in many living organisms (Blindauer, 2014). They have unique metal binding properties that ultimately result in the formation of characteristic metal-thiolate clusters. Due to the high abundance of Cys residues, they can also actively participate in scavenging reactive oxygen and nitrogen species (Ruttkay-Nedecky et al., 2013). The presence of MTs in bacteria (bacMTs) was considered as an exception more than a rule for a long time, but their ubiquity became evident in the last decade due to sequencing efforts of numerous bacterial strains (Blindauer, 2009). However,

Abbreviations: bacMTs, bacterial metallothioneins; CFU, colony-forming units; DMSO, dimethyl sulfoxide; EDTA, ethylenediaminetetraacetic acid; F-AAS, flame atomic absorption spectrometry; GmR, gentamycin resistance; LB, lysogeny broth; MIC, minimum inhibitory concentration; MT, metallothionein; ONPG, ortho-nitrophenyl- $\beta$-galactosidase; PCR, polymerase chain reaction; PflQ2 MT, metallothionein from Pseudomonas fluorescens Q2-87; PsdMT, Pseudomonas metallothionein; SDS, sodium dodecyl sulfate; TPEN, N,N,N'N'-tetrakis(2-pyridinylmethyl)-1,2-ethanediamine; TpR, trimethoprim resistant. 
a biological function of only two bacMTs has been investigated to date. SmtA from the Gram-negative cyanobacterium Synechococcus elongatus plays an essential role in zinc detoxification (Olafson et al., 1988; Robinson et al., 1990), while a MT from the pathogenic Gram-positive bacterium Mycobacterium tuberculosis (MymT) is crucial for copper detoxification (Gold et al., 2008).

Bioinformatic analysis of newly sequenced bacterial genomes has revealed that MTs are conserved in $90 \%$ of the Pseudomonas species (Winsor et al., 2016), including pathogenic (e.g., $P$. aeruginosa and $P$. entomophila) and non-pathogenic strains (e.g., P. fluorescens and P. putida), which implies their possible involvement in physiological processes necessary for survival in host and non-host environments (Figure 1). This emerging group of Pseudomonas MTs (PsdMTs) shows a conserved Cys distribution pattern with cyanobacterial MTs, suggesting similar metal preferences and biological functions. However, PsdMTs contain unique features both in their amino acid sequences (such as high abundance of His residues, an intrinsically disordered $\mathrm{C}$-term tail, and variations of the coordinating residues) and on the genomic level (see below). Recently, we determined the first 3D structure of a PsdMT from the P. fluorescens strain Q2-87 (PflQ2 MT) (Habjanic et al., 2018). Despite of the interesting novel features mentioned above, the overall structure of PflQ2 MT is similar to the structure of SmtA from S. elongatus (Blindauer et al., 2001) and coordination of four cadmium ions is observed (Figure 2). The binding capacity for zinc ions is, however, reduced to three in PflQ2MT compared to four in SmtA.

An important difference between SmtA and Pseudomonas MTs is their genetic organization. A number of cyanobacterial MTs including SmtA have a defined operon structure consisting of the MT, a zinc-dependent divergently transcribed repressor $(\mathrm{SmtB})$ and an operator-promoter region in the intergenic region (Huckle et al., 1993; Morby et al., 1993; Turner et al., 1996; Blindauer, 2008). In contrast, the Pseudomonas MT operon lacks metal-responsive regulators and its common promoter sequences. Furthermore, genes located upstream or downstream of the MT gene appear to be part of the same operon and code for proteins of unknown functions.

The genus Pseudomonas contains the largest number of described species among the Gram-negative bacteria. The members of the genus are metabolically versatile with the exceptional ability to survive in heterogeneous, dynamic and hostile environments (Silby et al., 2011; Gomila et al., 2015). The last decade saw an increased interest in understanding the heavy metal metabolism in Pseudomonas, and in particular the zinc homeostasis, owing to the importance of heavy metal homeostasis at the host/pathogen interface (Higham et al., 1984; D'Orazio et al., 2015; Pederick et al., 2015; Palmer and Skaar, 2016; Mastropasqua et al., 2017). It was found that the MT from $P$. aeruginosa PAO1 is present in biofilms (Hentzer et al., 2005; Waite et al., 2005, 2006) and its transcription was found to be upregulated in burn and chronic wounds (Turner et al., 2014). Similarly, the presence of elevated MT transcripts was confirmed in P. aeruginosa N6P6 biofilms and was also detected in response to elevated $\mathrm{Pb}^{\mathrm{II}}$ concentrations (Kumari and Das, 2019). However, in all these reports, the specific functions of the respective MT or its relevance for survival were not further investigated. To unravel the biological function of Pseudomonas MTs and their regulation, we used the P. fluorescens strain Q2-87 as a model since the structure of PflQ2 MT was determined recently (Figure 2; Habjanic et al., 2018). In this study, we focused on the involvement of this PsdMT in maintaining zinc homeostasis, including zinc limitation and excess, and its potential role in cadmium detoxification and stress response.

\section{MATERIALS AND METHODS}

\section{Bacterial Strains, Plasmids, and Media}

Bacterial strains and plasmids used in this study are listed in Supplementary Tables S1, S2, while primers are listed in Supplementary Table S3. The model strain used in this study, P. fluorescens Q2-87, was isolated from wheat rhizosphere (Washington, United States) (Loper et al., 2012). Genomic DNA was extracted using the DNeasy Blood \& Tissue Kit (Qiagen, Hilden, Germany) while plasmid DNA was extracted with the QIAprep Spin Miniprep kit (Qiagen) using standard protocols. All solutions and media were prepared with distilled $\mathrm{H}_{2} \mathrm{O}$ and sterilized for $20 \mathrm{~min}$ at $121^{\circ} \mathrm{C}$ and 1.2 bar unless stated otherwise. For DNA work and solutions that cannot be autoclaved Milli-Q water was used, and solutions were filtered using a $0.22 \mu \mathrm{m}$ vacuum filtration system (Steriflip, Merck Millipore, United States). For solid media, 1.5\% (w/v) of agar was added prior to autoclaving. P. fluorescens strains were grown at $30^{\circ} \mathrm{C}$ in lysogeny broth (LB) medium or the ABG minimal media (Clark and Maale, 1967) that was modified by replacing the phosphate buffer component with $250 \mathrm{mM}$ HEPES, $\mathrm{pH}$ 7.4 and supplemented additionally with $0.2 \%$ of yeast extract solution in order to boost the growth. Both LB and modified ABG minimal media contain similar amounts of $\mathrm{Zn}^{\mathrm{II}}$ (13 and $10 \mu \mathrm{M}$, respectively).

E. coli strains SY327 $\lambda$ pir and Top 10 were used as cloning hosts and were grown at $37^{\circ} \mathrm{C}$ in LB. Antibiotics were added to the following final concentrations: $50 \mu \mathrm{g} \mathrm{mL}^{-1}$ trimethoprim, $10 \mu \mathrm{g} \mathrm{mL}^{-1}$ tetracycline, $20 \mu \mathrm{g} \mathrm{mL}^{-1}$ gentamycin, $50 \mu \mathrm{g} \mathrm{mL}^{-1}$ kanamycin, $100 \mu \mathrm{g} \mathrm{mL}^{-1}$ ampicillin. Bacterial cultures were stored in $25 \%$ glycerol at $-80^{\circ} \mathrm{C}$.

The metal ion stocks of cadmium and zinc ions were prepared by dissolving $\mathrm{ZnCl}_{2}$ and $\mathrm{CdCl}_{2} \cdot 2.5 \mathrm{H}_{2} \mathrm{O}$ (Sigma Aldrich, Buchs, Switzerland) in Milli-Q water. The final concentration of metal ion stock solutions was measured using a flame atomic absorption spectrometer (F-AAS; AA240FS spectrometer (Agilent Technologies AG, Basel, Switzerland).

\section{Construction of MT Gene Knockout}

In order to ensure targeted, non-polar unmarked gene deletion, a mutagenesis system based on the homing endonuclease I-SceI was used (Supplementary Figure S1; Flannagan et al., 2008). Since this mutagenesis system was to the best of our knowledge for the first time applied on a $P$. fluorescens strain, conditions and the antibiotic selection procedure had to be thoroughly optimized. Since P. fluorescens is trimethoprim resistant $\left(\mathrm{Tp}^{\mathrm{R}}\right)$, 


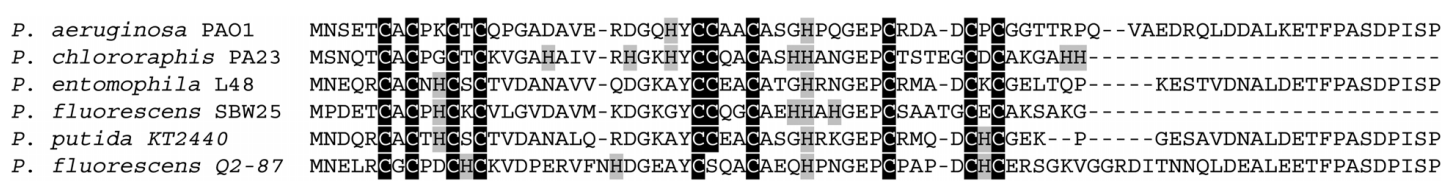

FIGURE 1 | Pseudomonas MTs. Amino acid sequences alignment of MTs from different Pseudomonas species. Cys residues are highlighted in black, His residues in gray.

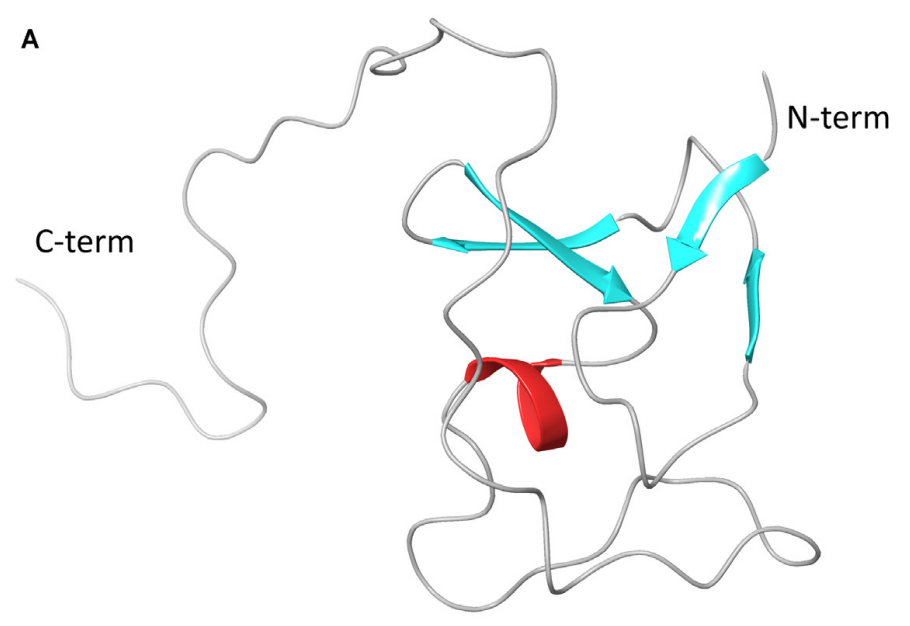

B

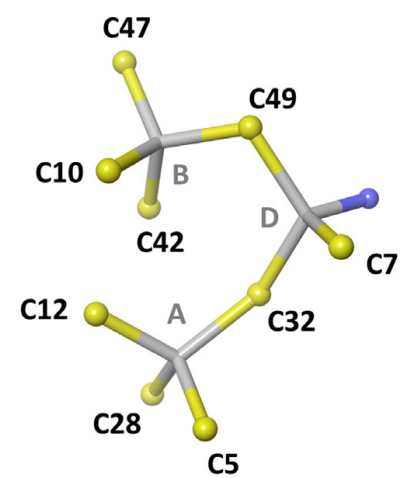

C

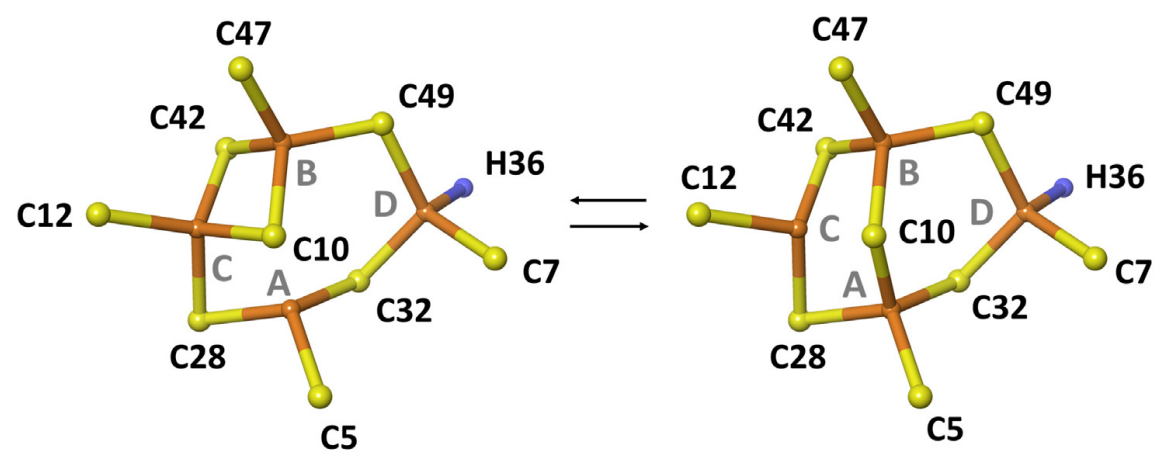

FIGURE 2 | Structure of MT from P. fluorescens Q2-87. (A) Representative structure of the protein backbone fold. (B) Topology of $\mathrm{Zn}_{3}$ Cys ${ }_{9} H$ is cluster. (C) Topology of $\mathrm{Cd}_{4}$ Cys 9 His cluster. (B,C) are reproduced from Habjanic et al. (2018) with permission from The Royal Society of Chemistry.

additionally a tetracycline antibiotic cassette was cloned into the suicide plasmid pGPI-SceI that has an I-SceI recognition site. The tetracycline resistance cassette was amplified from the shuttle plasmid pMe6032 (Heeb et al., 2002) using primers listed in Supplementary Table $\mathbf{S} 3$ and inserted into the pGPI-SceI plasmid using the Pst1 restriction site. Clones were selected using tetracycline, and the product (pGPI-SceI_tetR) was additionally confirmed by polymerase chain reaction (PCR) using the same primers used for the amplification of the tetracycline resistance cassette.

Regions of homology, MT_up and MT_down, that flank the MT gene targeted for the deletion were amplified using primers listed in Supplementary Table S3 and cloned into a newly constructed pGPI-SceI_tetR plasmid. Clones were selected using tetracycline and additionally confirmed by PCR using the same primers used for the amplification of homology regions. The constructed plasmid was introduced by triparental mating into P. fluorescens Q2-87 using the pRK2013 helper plasmid, which resulted in the integration of the plasmid into the genome by homologous recombination. The product of the first conjugation step was selected using tetracycline and confirmed by PCR using two sets of Pseudomonas specific primers, i.e., MT_up_Kpn1_fwd and MT_dn_EcoR1_rev (Supplementary Table S3).

The plasmid pDAI-SceI, which expresses the I-SceI nuclease and carries a gentamycin resistance $\left(\mathrm{Gm}^{\mathrm{R}}\right)$, was inserted into the product of the first step by triparental mating using pRK2013 as a helper strain. I-SceI expression resulted in cleavage at the I-SceI recognition site, producing a double strand break in the genomic DNA. This DNA break stimulates the host recombination/repair machinery resulting in two possible scenarios. The first scenario 
is removing the intervening sequences between MT_up and MT_dn resulting in the MT gene deletion, while the second scenario includes recombination that occurs between the MT_up and MT_dn region resulting in repair and recovery of the wild type form of $P$. fluorescens Q2-87. The final product, $\Delta \mathrm{MT}$ P. fluorescens Q2-87, was confirmed with PCR (Supplementary Figure S2) and by sequencing.

\section{Construction of Transcriptional lacZ Fusions and $\beta$-Galactosidase Assay}

The BPROM prediction server for bacterial promoters (Solovyev and Salamov, 2011) predicted two possible promoters (Supplementary Figure S3) forming two probable promoter regions, a bigger (L) and a smaller (S) one. Both regions were amplified using primers listed in Supplementary Table S3, digested with XhoI and HindIII restriction enzymes, and inserted into the reporter plasmid pSU11 (Malott et al., 2009). The resulting plasmids (pSU11/Lprom-lacZ; pSU11/SpromlacZ) were transferred to $P$. fluorescens Q2-87 by triparental mating using the helper plasmid (pRK2013). The resulting transconjugants were verified with two sets of primers, the forward and reverse primers used for amplification of promoter regions, and with a set including the forward primer from the amplification and reverse primer specific for the pSU11 plasmid (Supplementary Table S3).

The $\beta$-galactosidase assay was performed as previously described with minor modifications (Miller and Mekalanos, 1988). Briefly, cells were harvested and resuspended in Z-buffer (see appendix, $1 \mathrm{~mL}$ ), and the $\mathrm{OD}_{600}$ was measured. Cells were lysed using chloroform $(25 \mu \mathrm{L})$, sodium dodecyl sulfate (SDS; $25 \mu \mathrm{L}, 0.01 \%$ ) and briefly vortexed. The resulting mixture was incubated for $10 \mathrm{~min}$ at $28^{\circ} \mathrm{C}$. The reaction was initiated by adding ortho-Nitrophenyl- $\beta$-galactosidase (ONPG; $200 \mu \mathrm{L}$, $10 \mathrm{mg} / \mathrm{mL})$, and stopped with $\mathrm{Na}_{2} \mathrm{CO}_{3}(500 \mu \mathrm{L}, 1 \mathrm{M})$. Cell debris was removed by centrifugation (10 $\mathrm{min}, 15,000 \mathrm{rpm})$ and the absorbance at $420 \mathrm{~nm}$ was measured. The $\beta$-galactosidase activity was calculated using the following equation:

$$
\text { Activity [Miller units }]=\frac{1000 \times \mathrm{OD}_{420}}{\text { time }[\mathrm{min}] \times \mathrm{V}[\mathrm{mL}] \times 0 \mathrm{D}_{600}}
$$

\section{Growth Assay and Determination of MIC}

The minimum inhibitory concentration (MIC) of $P$. fluorescens Q2-87 and its $\triangle \mathrm{MT}$ mutant was determined by measuring the $\mathrm{OD}_{600}$ after $12 \mathrm{~h}$ incubation at $30^{\circ} \mathrm{C}, 220 \mathrm{rpm}$ upon addition of different concentrations of $\mathrm{Zn}^{\mathrm{II}}$ and $\mathrm{Cd}^{\mathrm{II}}$ ions. Additionally, the growth of both strains was monitored in $1 \mathrm{~h}$ increments for a total of $12 \mathrm{~h}$ by measuring the $\mathrm{OD}_{600}$ in the presence of $25 \mu \mathrm{M} \mathrm{Cd}^{\mathrm{II}}$ or $50 \mu \mathrm{M} \mathrm{Zn}{ }^{\mathrm{II}}$. In both experiments, cultures without the addition of metal ions were used as a control.

\section{Biofilm Formation and Quantification}

An overnight bacterial culture was subcultured into modified ABG-media to a starting $\mathrm{OD}_{600}$ of 0.03 and transferred in $200 \mu \mathrm{L}$ aliquots into a round-bottom 96-well microtiter plate (Sarstedt, Switzerland). The plate was incubated for $48 \mathrm{~h}$ at $10^{\circ} \mathrm{C}$. After incubation, growth was checked by measuring $\mathrm{OD}_{550}$ in the plate reader (Biotek, PowerWave XS2), $100 \mu \mathrm{L}$ of $0.1 \%(\mathrm{w} / \mathrm{v})$ crystal violet (triarylmethane) solution was added into each well and incubated for $30 \mathrm{~min}$ at room temperature. Afterward, the media was discarded, wells washed carefully with distilled water in order to remove the planktonic cells and the plate was left at room temperature to dry. To solubilize the crystal violet, $200 \mu \mathrm{L}$ of dimethyl sulfoxide (DMSO) was added to each well and incubated for $20 \mathrm{~min}$ at room temperature. The content of each well was transferred into a flat-bottom 96-well plate and the absorbance at $570 \mathrm{~nm}$ was measured in order to quantify the biofilms.

\section{Motility Assay}

Swarming and swimming motility was determined on agar plates using modified ABG-media using $0.4 \%(\mathrm{w} / \mathrm{v})$ and $0.3 \%(\mathrm{w} / \mathrm{v})$ of agar respectively (Eberl et al., 1996). Plates were inoculated with overnight bacterial culture by stabbing with a sterile toothpick for swimming motility or spotting $2.5 \mu \mathrm{L}$ of bacterial culture in the center for swarming motility. The plates were incubated at $28^{\circ} \mathrm{C}$ for $24 \mathrm{~h}$.

\section{Tagging Bacteria With Mini-Tn7 System}

$P$. fluorescens Q2-87 as well as the $\Delta \mathrm{MT}$ knock strain were tagged with $\mathrm{mCherry} / \mathrm{Gn}^{\mathrm{R}}$ using the mini-Tn7 system. For triparental mating, recipient (P. fluorescens Q2-87/ $\Delta \mathrm{MT}$ ), donor [E. coli S17-1 containing mini-Tn7 plasmid (pMRE100)] and helper (E. coli S-17-1 carrying pUX-BF13 plasmid) strains were used. The products of the conjugation were selected using both ampicillin and gentamycin.

\section{Bacterial Competition Assay}

P. fluorescens strains (Q2-87 $\left.\triangle \mathrm{MT}, \mathrm{Q} 2-87 \_\mathrm{mCherry}\right)$ were grown overnight at $30^{\circ} \mathrm{C}$ in modified ABG media (see above). Each culture for the competition assay was added to modified ABG

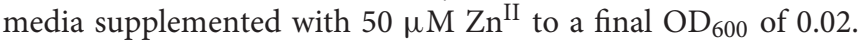
After a growth period of $24-120 \mathrm{~h}$ at $30^{\circ} \mathrm{C}$, serial dilutions $\left(10^{-1}\right.$ to $10^{-7}$ ) of bacterial cultures were plated on LB agar plates (with and without gentamycin). Plates were incubated overnight at $30^{\circ} \mathrm{C}$, and the number of viable colony-forming units (CFU) was counted and used to calculate the CFU/mL for all culture tested. All experiments were carried out at least three times.

\section{RESULTS AND DISCUSSION}

\section{PfIQ2 MT Is Dispensable for Zinc Homeostasis and Cadmium Detoxification}

To directly assess the role of the putative metallothionein PflQ2 MT of $P$. fluorescens Q2-87, a mutant strain defective in the production of this $\mathrm{MT}(\triangle \mathrm{MT})$ was constructed. Since previous in vitro studies suggested that PflQ2 MT binds zinc and cadmium ions (Habjanic et al., 2018), the role of PflQ2 MT in metal resistance was assessed by determining the minimal inhibitory concentrations (MIC) of the wild type and the mutant strain to these two metal ions. Both 
the Q2-87 wild-type and the DMT mutant strains showed a growth impairment already at low $\mathrm{Zn}^{\mathrm{II}}$ and $\mathrm{Cd}^{\mathrm{II}}$ concentrations of 25 and $5 \mu \mathrm{M}$, respectively (Supplementary Figure S4). However, no significant difference in growth between the two strains was observed with or without the addition of inhibitory concentrations of $\mathrm{Zn}{ }^{\mathrm{II}}$ and $\mathrm{Cd}^{\mathrm{II}}$ (Figure 3 and Supplementary Figure S5). Similar results were also obtained in the presence of different concentrations of the metal chelator EDTA (ethylenediaminetetraacetic acid) or TPEN [N, $\mathrm{N}, \mathrm{N}, \mathrm{N}^{\prime}$-tetrakis(2-pyridinylmethyl)-1,2-ethanediamine] (data not shown).

The similar growth pattern of the wild type and mutant strain under $\mathrm{Zn}^{\mathrm{II}} / \mathrm{Cd}^{\mathrm{II}}$ excess as well as metal-limited conditions suggest that PflQ2 MT is neither critical for metal resistance nor for metal uptake in P. fluorescens Q2-87.

\section{MT Expression Is Elevated in the Stationary Growth Phase}

To elucidate the putative function of PflQ2 MT in growth and survival of $P$. fluorescens under different conditions, we analyzed the activity of the PflQ2 MT promoter. Two putative bacterial sigma70-dependent promoter regions were identified using BROM (Solovyev and Salamov, 2011). One of these putative promoters was found to be located 922 nucleotides upstream of the MT gene (Lprom), while the second one was identified 594 nucleotides upstream of the MT gene (Sprom) (Supplementary Figure S3). To study the regulation of MT gene expression, transcriptional fusions of the two putative promoter regions to the reporter gene lac $Z$ were generated. The resulting fusions and the empty vector as a control were transformed into the $P$. fluorescens wild-type strain and

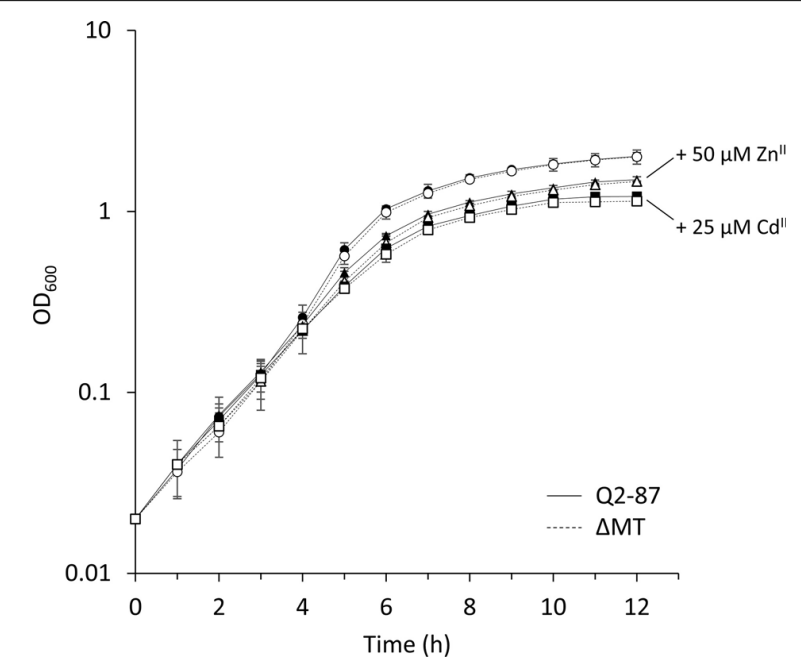

FIGURE 3 | The effect of $Z n^{\|}$and $C d^{\prime \prime}$ on $P$. fluorescens growth. Growth of P. fluorescens Q2-87 and the $\Delta \mathrm{MT}$ mutant was compared by optical density measurements at $600 \mathrm{~nm}$ upon addition of $50 \mu \mathrm{M} \mathrm{Zn}$ " or $25 \mu \mathrm{M}$ Cd". Data are presented as the mean of three independent experiments and the standard deviation is given as error bars. See Supplementary Figure S5 for linear growth scale. $\beta$-galactosidase activities were determined under various growth conditions, including the addition of different d-block metal ions $\left(\mathrm{Zn}^{\mathrm{II}}, \mathrm{Cd}^{\mathrm{II}}, \mathrm{Cu}^{\mathrm{II}}, \mathrm{Hg}^{\mathrm{II}}\right)$, oxidative stress induced by addition of hydrogen peroxide or tert-butyl hydroperoxide, and nitrosative stress induced by peroxynitrite and S-nitrosoglutathione. The results show that Sprom_pSU11 and the vector control display very low $\beta$-galactosidase activities, while Lprom_pSU11 displays significantly higher activities depending on the respective concentrations and the growth conditions (Supplementary Figure S6). Therefore, Lprom is the most probable MT promoter candidate, and the respective transcriptional fusion was used in all subsequent experiments.

We next grew this strain in the absence or presence of inhibitory concentrations of $\mathrm{Zn}^{\mathrm{II}}(50 \mu \mathrm{M}), \mathrm{Cd}^{\mathrm{II}}(25 \mu \mathrm{M})$, TPEN $(25 \mu \mathrm{M})$, and EDTA $(50 \mu \mathrm{M})$ for $48 \mathrm{~h}$ (Figure 4 and Supplementary Figure S7). Surprisingly, the MT promoter activity was only slightly increased in the exponential phase of growth, while it increased 10 to 20 -fold when the bacteria entered the stationary phase after 24 to $48 \mathrm{~h}$. However, this difference was not observed in media supplemented with TPEN where the level of MT expression remained the same throughout the experiment. While the stability constants of EDTA and TPEN for $\mathrm{Zn}^{\mathrm{II}}$ are in the same range ( $10^{15.4}$ and $10^{15.2} \mathrm{M}^{-1}$, respectively) (Radford and Lippard, 2013), TPEN readily permeates cell membranes (Arslan et al., 1985) and accordingly limits the intracellular availability of $\mathrm{Zn}^{\mathrm{II}}$.

The key finding that the MT is highly expressed in the stationary phase of $P$. fluorescens growth under normal conditions and in the presence of inhibitory concentrations of $\mathrm{Cd}^{\mathrm{II}}$ and $\mathrm{Zn}^{\mathrm{II}}$ suggests that PflQ2 $\mathrm{MT}$ is probably important for long-term survival of the bacterium. To further evaluate this hypothetical role, we tested if increasing cadmium and zinc concentrations result in even higher MT promoter activity after $48 \mathrm{~h}$ of incubation. No correlation between the promoter activities and $\mathrm{Cd}^{\mathrm{II}}$ concentrations was observed, while MT expression further increased with higher concentrations of $\mathrm{Zn}^{\mathrm{II}}$ concomitant with a slight reduction of growth (Figure 5A and Supplementary Figure S8A). Although the addition of inhibitory concentrations of $\mathrm{Zn}^{\mathrm{II}}$ and $\mathrm{Cd}^{\mathrm{II}}$ during the exponential phase $\left(\mathrm{OD}_{600}=0.55\right)$ and incubation for $2 \mathrm{~h}$ did not induce MT transcription, a decline in growth with increasing metal concentrations was observed (Figure 5B and Supplementary Figure S8B). Likewise, addition of the same inhibitory concentrations after $48 \mathrm{~h}$ of growth did not further induce the already elevated expression levels (Figure 5C).

It is noteworthy that the addition of inhibitory concentrations of different oxidative and nitrosative stress inducing agents as well as limiting the amount of glucose and yeast extract did not increase the expression of MT in the exponential or the stationary growth phase, ruling out the potential role of MT in stress response (data not shown).

\section{MT Is Not Crucial for Biofilm Formation, Motility, and Viability}

In contrast to planktonic cultures, an MT is found among the differentially expressed genes in $P$. aeruginosa biofilms 

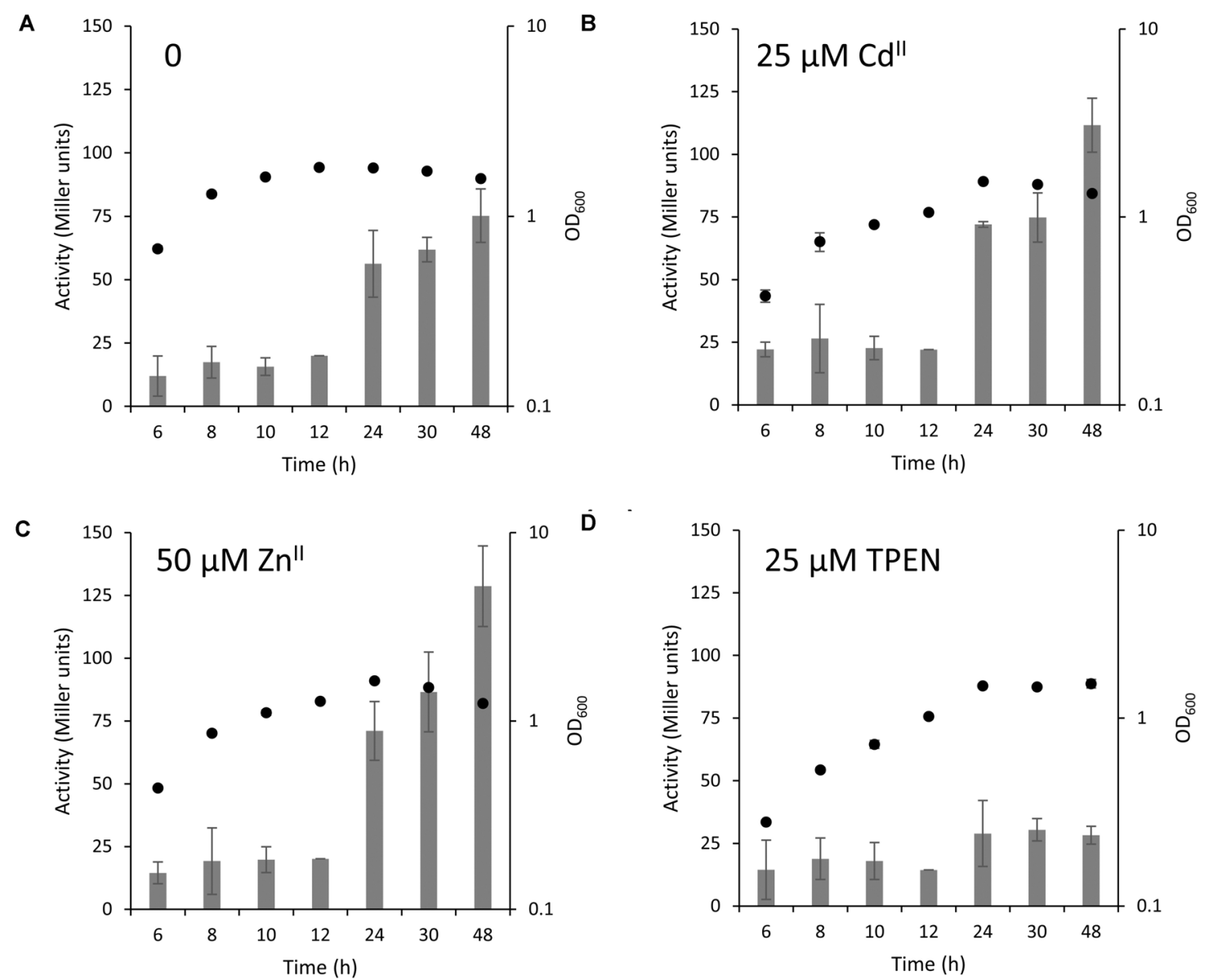

E

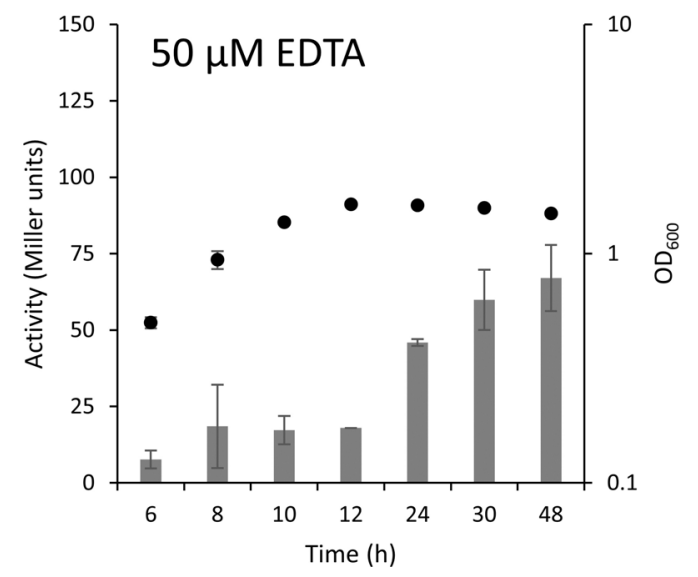

FIGURE 4 | MT expression in different stages of bacterial growth. MT expression in the wild type Q2-87 in modified ABG medium is depicted in form of bars in Miller

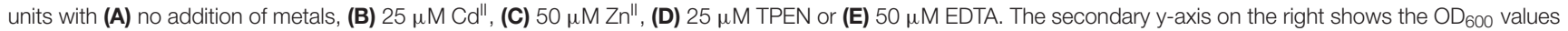
of bacterial culture at the time samples were taken (black full circles). See Supplementary Figure $\mathbf{S 7}$ for linear growth scale.

(Hentzer et al., 2005; Waite et al., 2005, 2006). Therefore, we investigated the importance of Pfl2 MT for biofilm formation. Interestingly, P. fluorescens Q2-87 cells formed a biofilm in microtiter plates only at $10^{\circ} \mathrm{C}$ but not at $30^{\circ} \mathrm{C}$. No significant difference in biofilm formation between the wild-type Q2-87 and the $\Delta \mathrm{MT}$ mutant strain was observed, neither under normal growth conditions nor in the presence of inhibitory concentrations of $\mathrm{Zn}^{\mathrm{II}}$ or $\mathrm{Cd}^{\mathrm{II}}$ (Supplementary Figure S9). Since biofilm formation is strongly influenced by cell motility, the swarming and 
A

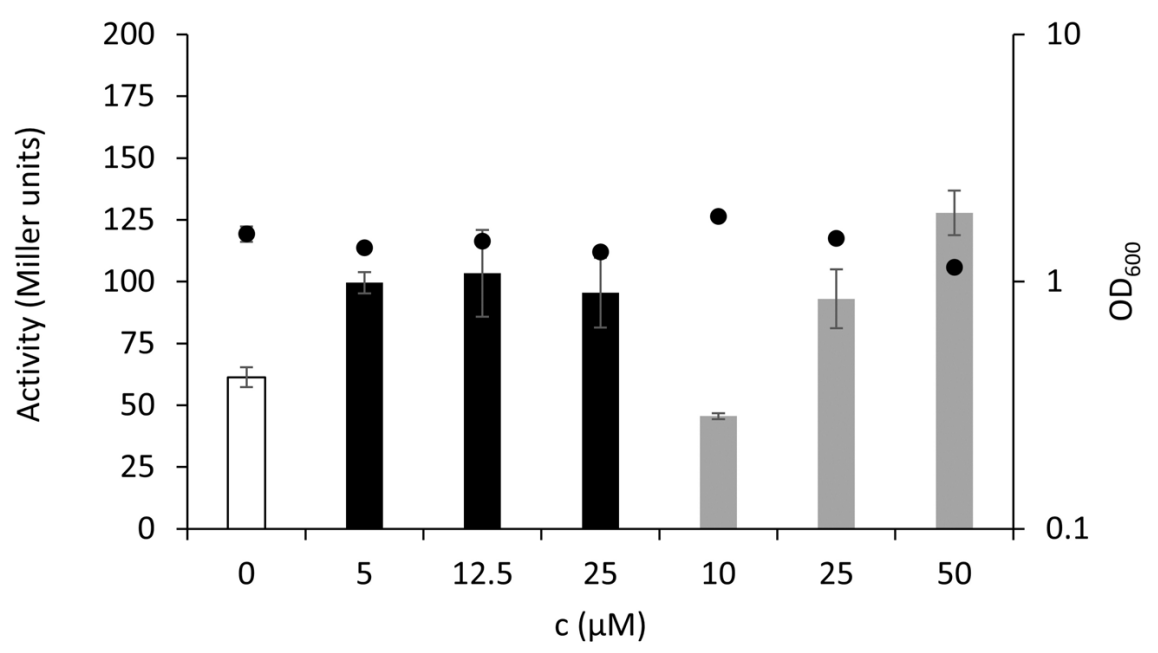

B

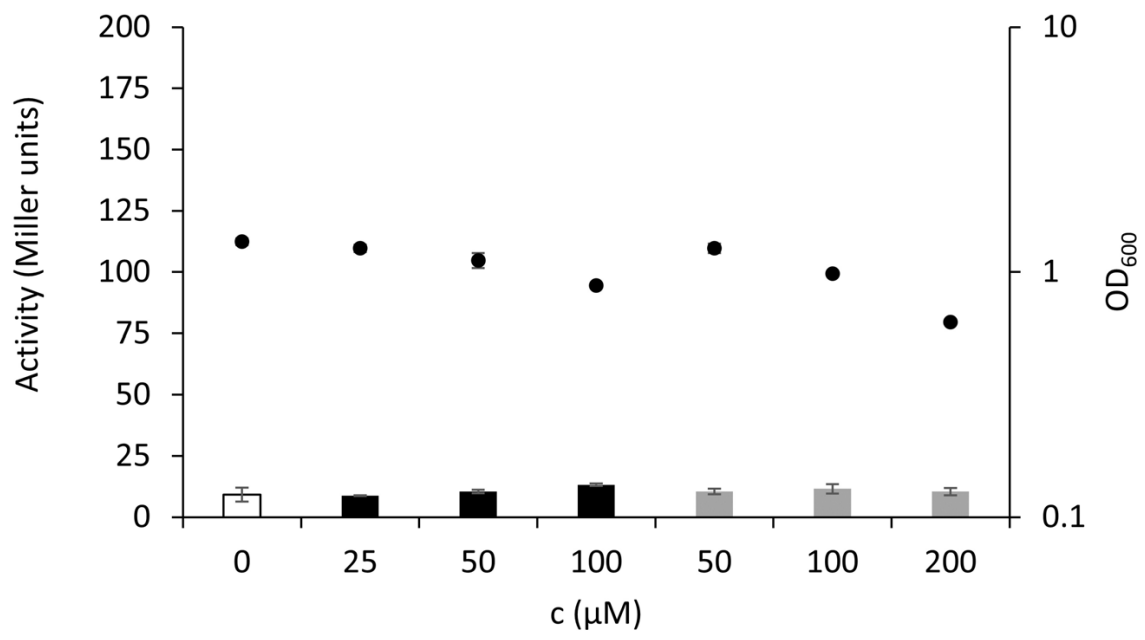

C

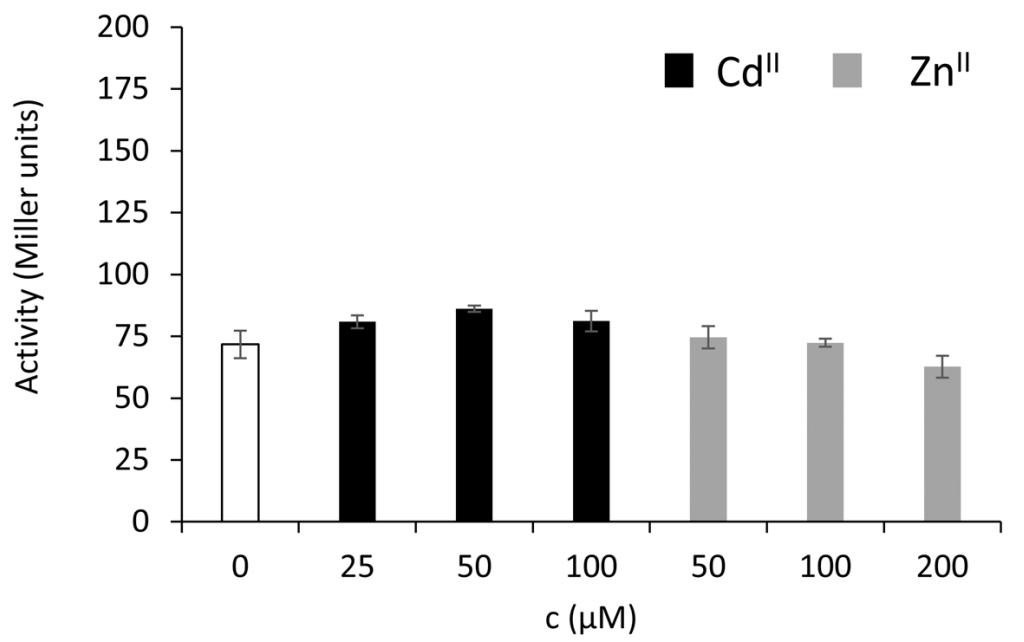

FIGURE 5 | Level of MT expression in the stationary and exponential phase of growth. MT expression without additional metal ions (white bars) or in the presence of different concentrations of $\mathrm{Zn}^{\text {Il }}$ (gray bars) or $\mathrm{Cd}^{\text {Il }}$ (black bars) during mid-exponential phase of bacterial growth is given in Miller units and depicted after (A) $48 \mathrm{~h}$ incubation or (B) $2 \mathrm{~h}$ incubation. In (C) the different concentrations of $\mathrm{Zn}^{\text {Il }}$ or $\mathrm{Cd}^{\text {Il }}$ were added after $48 \mathrm{~h}$ of bacterial growth followed by $2 \mathrm{~h}$ incubation. The secondary $\mathrm{y}$-axis on the right in $\mathbf{( A , B )}$ represents $\mathrm{OD}_{600}$ values at the time samples were taken (black full circles). See Supplementary Figure S8 for linear growth scale. 

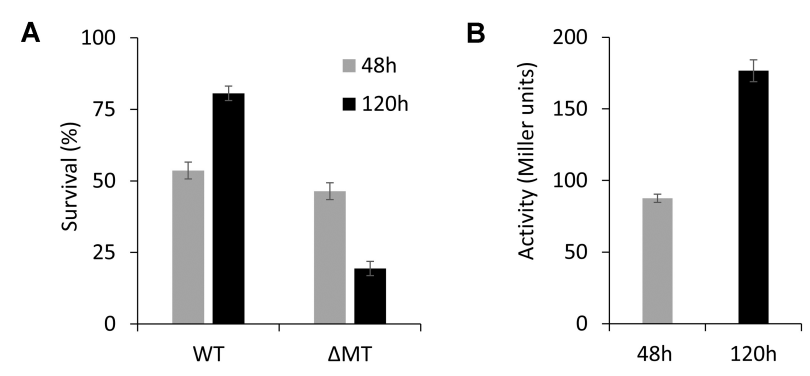

FIGURE 6 | WT vs. $\triangle \mathrm{MT}$ competition study. (A) Percentage of survived bacteria after $48 \mathrm{~h}(\mathrm{WT}: \Delta \mathrm{MT}=54: 46)$ and $120 \mathrm{~h}(\mathrm{WT}: \Delta \mathrm{MT}=81: 19)$ incubation of cultures containing the mixed WT and $\Delta \mathrm{MT}$ strains.

(B) Expression levels of MT under the conditions given in (A)

swimming abilities of the two strains were tested. No significant difference in swimming was observed between the wild type and mutant in the presence or absence of inhibitory concentrations of $\mathrm{Zn}^{\mathrm{II}} / \mathrm{Cd}^{\mathrm{II}}$ (Supplementary Figure S10). The strains did not exhibit swarming motility under any of the tested conditions. Taken together, our results suggest that PflQ2 MT is not required for biofilm formation in P. fluorescens Q2-87.

As many proteins synthesized at the transition to the stationary phase are involved in survival during nutrient deprivation, the role of MT in the viability of $P$. fluorescens Q2-87 was analyzed by determining the viable cell counts of the wild type and mutant strain. No difference in the number of viable cells was observed after 24 and $48 \mathrm{~h}$ incubation (data not shown), suggesting that the MT is not essential for starvation survival of $P$. fluorescens over this time period.

\section{MT Is Important in the Long-Term Survival of $P$. fluorescens}

Our finding that MT expression is upregulated in the stationary growth phase suggests that MT can provide a competitive advantage to $P$. fluorescens in long-term survival. To investigate this, competition studies between a mCherry-marked wild-type derivative and the $\triangle \mathrm{MT}$ mutant strain were performed in modified ABG media containing $50 \mu \mathrm{M} \mathrm{Zn}^{\mathrm{II}}$. The viability of the bacteria was determined after 48 and $120 \mathrm{~h}$ by plating on LB medium. Our results show that there is no significant difference in the cell counts after $48 \mathrm{~h}$ (Figure 6A). However, we observed that there was a decline in the viability of the $\Delta \mathrm{MT}$ mutant by $\sim 20 \%$ after $120 \mathrm{~h}$, which can be correlated to the increased expression of PflQ2 at the same time point (Figures 6A,B), suggesting that the MT confers a competitive advantage for the long-term survival of $P$. fluorescens.

\section{CONCLUSION}

Since most studies on metal ion homeostasis and detoxification in Pseudomonas species were performed during the exponential phase of bacterial growth, the role of PsdMTs has remained elusive. Here, we investigated the role of MT in zinc homeostasis and cadmium detoxification using $P$. fluorescens Q2-87 as a model strain. Intriguingly, significant MT expression was detected only after $12 \mathrm{~h}$ of incubation when bacterial cultures entered the stationary growth phase. Therefore, the MT does not seem to play a role in zinc homeostasis and cadmium detoxification in $P$. fluorescens during exponential growth. However, our competition studies provide evidence that the MT significantly supports the long-term viability of $P$. fluorescens Q2-87. It is generally assumed that the majority of the bacteria experience nutrient deprivation, exposure to toxic waste products and various stresses such as $\mathrm{pH}$, temperature and osmolality in their natural environments (Kram and Finkel, 2014; Jaishankar and Srivastava, 2017). Consequently, bacteria induce the expression of specific genes that help to increase their competitive fitness. Our finding that exposure to inhibitory concentrations of zinc and cadmium ions increased MT expression in the stationary phase suggests that MT may play a role in the storage or sequestration of metals when present in excess. In conclusion, this study reinforces the importance of MTs in metal homeostasis in $P$. fluorescens and provides evidence for a specific role in starvation survival.

\section{DATA AVAILABILITY STATEMENT}

All datasets presented in this study are included in the article/Supplementary Material.

\section{AUTHOR CONTRIBUTIONS}

$\mathrm{JH}$ planned and performed the experiments and wrote the manuscript. AM planned and supervised the experiments and helped writing the manuscript. LE planned the experiments and helped writing the manuscript. EF planned and discussed the experiments and wrote the manuscript. All authors contributed to the article and approved the submitted version.

\section{FUNDING}

The work was financially supported by the Forschungskredit of the University of Zurich, Grant Nos. (FK-15-085 and FK-17091) to JH.

\section{ACKNOWLEDGMENTS}

We thank Dr. Monika Maurhofer (ETHZ) for providing the Pseudomonas fluorescens Q2-87 strain.

\section{SUPPLEMENTARY MATERIAL}

The Supplementary Material for this article can be found online at: https://www.frontiersin.org/articles/10.3389/fmicb.2020. 01709/full\#supplementary-material 


\section{REFERENCES}

Arslan, P., Divirgilio, F., Beltrame, M., Tsien, R. Y., and Pozzan, T. (1985). Cytosolic $\mathrm{Ca} 2+$ homeostasis in Ehrlich and Yoshida carcinomas. A new, membranepermeant chelator of heavy-metals reveals that these ascites tumor cell lines have normal cytosolic free Ca2+. J. Biol. Chem. 260, 2719-2727.

Blindauer, C. A. (2008). Zinc-handling in cyanobacteria: an update. Chem. Biodivers. 5, 1990-2013. doi: 10.1002/cbdv.200890183

Blindauer, C. A. (2009). Bacterial metallothioneins. Met. Ions Life Sci. 5, 51-81. doi: 10.1039/9781847559531-00051

Blindauer, C. A. (2014). "Metallothioneins," in Binding, Transport and Storage of Metal Ions in Biological Cells, eds W. Maret and A. G. Wedd (London: Royal Society of Chemistry), 606-665.

Blindauer, C. A. (2015). Advances in the molecular understanding of biological zinc transport. Chem. Commun. 51, 4544-4563. doi: 10.1039/c4cc10174j

Blindauer, C. A., Harrison, M. D., Parkinson, J. A., Robinson, A. K., Cavet, J. S., Robinson, N. J., et al. (2001). A metallothionein containing a zinc finger within a four-metal cluster protects a bacterium from zinc toxicity. Proc. Natl. Acad. Sci. U.S.A. 98, 9593-9598. doi: 10.1073/pnas.171120098

Clark, D. J., and Maale, O. (1967). DNA replication and the division cycle in Escherichia coli. J. Mol. Biol. 23, 99-112. doi: 10.1016/s0022-2836(67)80070-6

D’Orazio, M., Mastropasqua, M. C., Cerasi, M., Pacello, F., Consalvo, A., Chirullo, B., et al. (2015). The capability of Pseudomonas aeruginosa to recruit zinc under conditions of limited metal availability is affected by inactivation of the ZnuABC transporter. Metallomics 7, 1023-1035. doi: 10.1039/c5mt00017c

Eberl, L., Winson, M. K., Sternberg, C., Stewart, G. S., Christiansen, G., Chhabra, S. R., et al. (1996). Involvement of N-acyl-L-hormoserine lactone autoinducers in controlling the multicellular behaviour of Serratia liquefaciens. Mol. Microbiol. 20, 127-136. doi: 10.1111/j.1365-2958.1996.tb02495.x

Flannagan, R. S., Linn, T., and Valvano, M. A. (2008). A system for the construction of targeted unmarked gene deletions in the genus Burkholderia. Environ. Microbiol. 10, 1652-1660. doi: 10.1111/j.1462-2920.2008.01576.x

Gold, B., Deng, H., Bryk, R., Vargas, D., Eliezer, D., Roberts, J., et al. (2008). Identification of a copper-binding metallothionein in pathogenic mycobacteria. Nat. Chem. Biol. 4, 609-616. doi: 10.1038/nchembio.109

Gomila, M., Pena, A., Mulet, M., Lalucat, J., and Garcia-Valdes, E. (2015). Phylogenomics and systematics in Pseudomonas. Front. Microbiol. 6:214. doi: $10.3389 /$ fmicb.2015.00214

Habjanic, J., Zerbe, O., and Freisinger, E. (2018). A histidine-rich Pseudomonas metallothionein with a disordered tail displays higher binding capacity for cadmium than zinc. Metallomics 10, 1415-1429. doi: 10.1039/c8mt00193f

Heeb, S., Blumer, C., and Haas, D. (2002). Regulatory RNA as mediator in GacA/RsmA-dependent global control of exoproduct formation in Pseudomonas fluorescens CHA0. J. Bacteriol. 184, 1046-1056. doi: 10.1128/jb. 184.4.1046-1056.2002

Hentzer, M., Eberl, L., and Givskov, M. (2005). Transcriptome analysis of Pseudomonas aeruginosa biofilm development: anaerobic respiration and iron limitation. Biofilms 2, 37-61. doi: 10.1017/s1479050505001699

Higham, D. P., Sadler, P. J., and Scawen, M. D. (1984). Cadmium-resistant Pseudomonas putida synthesizes novel cadmium proteins. Science 225, $1043-$ 1046. doi: $10.1126 /$ science.225.4666.1043

Huckle, J. W., Morby, A. P., Turner, J. S., and Robinson, N. J. (1993). Isolation of a prokaryotic metallothionein locus and analysis of transcriptional control by trace metal ions. Mol. Microbiol. 7, 177-187. doi: 10.1111/j.1365-2958.1993. tb01109.x

Jaishankar, J., and Srivastava, P. (2017). Molecular basis of stationary phase survival and applications. Front. Microbiol. 8:2000. doi: 10.3389/fmicb.2017.02000

Kram, K. E., and Finkel, S. E. (2014). Culture volume and vessel affect long-term survival, mutation frequency, and oxidative stress of Escherichia coli. Appl. Environ. Microbiol. 80, 1732-1738. doi: 10.1128/aem.03150-13

Kumari, S., and Das, S. (2019). Expression of metallothionein encoding gene bmtA in biofilm-forming marine bacterium Pseudomonas aeruginosa N6P6 and understanding its involvement in $\mathrm{Pb}(\mathrm{II})$ resistance and bioremediation. Environ. Sci. Pollut. Res. Int. 26, 28763-28774. doi: 10.1007/s11356-01905916-2
Loper, J. E., Hassan, K. A., Mavrodi, D. V., Davis, E. W. II, Lim, C. K., Shaffer, B. T., et al. (2012). Comparative genomics of plant-associated Pseudomonas spp.: insights into diversity and inheritance of traits involved in multitrophic interactions. PLoS Genet. 8:e1002784. doi: 10.1371/journal.pgen.1002784

Malott, R. J., O’grady, E. P., Toller, J., Inhulsen, S., Eberl, L., and Sokol, P. A. (2009). A Burkholderia cenocepacia orphan LuxR homolog is involved in quorumsensing regulation. J. Bacteriol. 191, 2447-2460. doi: 10.1128/jb.01746-08

Maret, W., and Moulis, J. M. (2013). The bioinorganic chemistry of cadmium in the context of its toxicity. Met. Ions Life Sci. 11, 1-29. doi: 10.1007/978-94-0075179-8_1

Mastropasqua, M. C., D’orazio, M., Cerasi, M., Pacello, F., Gismondi, A., Canini, A., et al. (2017). Growth of Pseudomonas aeruginosa in zinc poor environments is promoted by a nicotianamine-related metallophore. Mol. Microbiol. 106, 543-561. doi: 10.1111/mmi.13834

Mikhaylina, A., Ksibe, A. Z., Scanlan, D. J., and Blindauer, C. A. (2018). Bacterial zinc uptake regulator proteins and their regulons. Biochem. Soc. Trans. 46, 983-1001. doi: 10.1042/bst20170228

Miller, V. L., and Mekalanos, J. J. (1988). A novel suicide vector and its use in construction of insertion mutations: osmoregulation of outer membrane proteins and virulence determinants in Vibrio Cholerae requires toxR. J. Bacteriol. 170, 2575-2583. doi: 10.1128/jb.170.6.2575-2583.1988

Morby, A. P., Turner, J. S., Huckle, J. W., and Robinson, N. J. (1993). SmtB is a metal-dependent repressor of the cyanobacterial metallothionein gene smtA: identification of a Zn inhibited DNA-protein complex. Nucleic Acids Res. 21, 921-925. doi: 10.1093/nar/21.4.921

Olafson, R. W., Mccubbin, W. D., and Kay, C. M. (1988). Primary- and secondary-structural analysis of a unique prokaryotic metallothionein from a Synechococcus sp. cyanobacterium. Biochem. J. 251, 691-699. doi: 10.1042/ bj2510691

Palmer, L. D., and Skaar, E. P. (2016). Transition metals and virulence in bacteria. Annu. Rev. Genet. 50, 67-91. doi: 10.1146/annurev-genet-120215-035146

Pederick, V. G., Eijkelkamp, B. A., Begg, S. L., Ween, M. P., Mcallister, L. J., Paton, J. C., et al. (2015). ZnuA and zinc homeostasis in Pseudomonas aeruginosa. Sci. Rep. 5:13139.

Radford, R. J., and Lippard, S. J. (2013). Chelators for investigating zinc metalloneurochemistry. Curr. Opin. Chem. Biol. 17, 129-136. doi: 10.1016/j. cbpa.2013.01.009

Robinson, N. J., Gupta, A., Fordham-Skelton, A. P., Croy, R. R., Whitton, B. A., and Huckle, J. W. (1990). Prokaryotic metallothionein gene characterication and expression: chromosome crawling by ligation-mediated PCR. Proc. Biol. Sci. 242, 241-247. doi: 10.1098/rspb.1990.0130

Ruttkay-Nedecky, B., Nejdl, L., Gumulec, J., Zitka, O., Masarik, M., Eckschlager, T., et al. (2013). The role of metallothionein in oxidative stress. Int. J. Mol. Sci. 14, 6044-6066. doi: 10.3390/ijms14036044

Silby, M. W., Winstanley, C., Godfrey, S. A., Levy, S. B., and Jackson, R. W. (2011). Pseudomonas genomes: diverse and adaptable. FEMS Microbiol. Rev. 35, $652-680$.

Solovyev, V., and Salamov, A. (2011). "Automatic annotation of microbial genomes and metagenomic sequences," in Metagenomics and its Applications in Agriculture, Biomedicine and Environmental Studies, ed. R. W. Li (Hauppauge, NY: Nova Science Publishers), 61-78.

Turner, J. S., Glands, P. D., Samson, A. C., and Robinson, N. J. (1996). Zn2+sensing by the cyanobacterial metallothionein repressor SmtB: different motifs mediate metal-induced protein-DNA dissociation. Nucleic Acids Res. 24, 37143721. doi: $10.1093 /$ nar/24.19.3714

Turner, K. H., Everett, J., Trivedi, U., Rumbaugh, K. P., and Whiteley, M. (2014). Requirements for Pseudomonas aeruginosa acute burn and chronic surgical wound infection. PLoS Genet. 10:e1004518. doi: 10.1371/journal.pgen.100 4518

Waite, R. D., Paccanaro, A., Papakonstantinopoulou, A., Hurst, J. M., Saqi, M., Littler, E., et al. (2006). Clustering of Pseudomonas aeruginosa transcriptomes from planktonic cultures, developing and mature biofilms reveals distinct expression profiles. BMC Genomics 7:162. doi: 10.1186/1471-2164-7-162

Waite, R. D., Papakonstantinopoulou, A., Littler, E., and Curtis, M. A. (2005). Transcriptome analysis of Pseudomonas aeruginosa growth: comparison of 
gene expression in planktonic cultures and developing and mature biofilms. J. Bacteriol. 187, 6571-6576. doi: 10.1128/jb.187.18.6571-6576.2005

Watly, J., Potocki, S., and Rowinska-Zyrek, M. (2016). Zinc homeostasis at the bacteria/host interface-from coordination chemistry to nutritional immunity. Chemistry 22, 15992-16010. doi: 10.1002/chem.20160 2376

Winsor, G. L., Griffiths, E. J., Lo, R., Dhillon, B. K., Shay, J. A., and Brinkman, F. S. (2016). Enhanced annotations and features for comparing thousands of Pseudomonas genomes in the Pseudomonas genome database. Nucleic Acids Res. 44, D646-D653.
Conflict of Interest: The authors declare that the research was conducted in the absence of any commercial or financial relationships that could be construed as a potential conflict of interest.

Copyright $\odot 2020$ Habjanič, Mathew, Eberl and Freisinger. This is an open-access article distributed under the terms of the Creative Commons Attribution License (CC BY). The use, distribution or reproduction in other forums is permitted, provided the original author(s) and the copyright owner(s) are credited and that the original publication in this journal is cited, in accordance with accepted academic practice. No use, distribution or reproduction is permitted which does not comply with these terms. 